\title{
DETERMINATION OF ARSENIC IN HELIANTHUS ANNUUS L. BY HYDRIDE GENERATION ATOMIC ABSORPTION SPECTROMETRY
}

\author{
GULAY S. ${ }^{1, *}$ \\ AYCA K. ${ }^{2}$ \\ YILDIZ K. ${ }^{3}$
}

\author{
${ }^{1}$ Faculty of Pharmacy, Department of Analytical Chemistry \\ Trakya University, Turkey \\ ${ }^{2}$ Department of Chemistry \\ Namik Kemal University, Tekirdag, Turkey \\ ${ }^{3}$ Department of Chemistry \\ Trakya University, Edirne, Turkey
}

Received: $13 / 05 / 2014$

Accepted: 07/01/2014

Available online: 15/01/2014 *to whom all correspondence should be addressed: e-mail: gulayseren@trakya.edu.tr

\begin{abstract}
This study represents new research on the sunflower (Helianthus annuus L.) including new data on arsenic contents in Ergene River Basin. In this study, the concentrations of arsenic in soil and sunflower plant have been investigated. The area has suffered significant pollution as a result of industrial and agricultural activities in Turkey. Sunflower are produced in this area that approximately \%70 in Turkey. Arsenic concentrations in H.annuus L. plants collected from different regions in Turkey were determined by hydride-generation atomic absorption spectrometry (HGAAS) after microwave-assisted acid digestion of samples. The accuracy of the techniques was evaluated by using certified reference materials; NIMGBW07404 (GSS-4) for soil and WEPAL-IPE-168 for sunflower plant. The precision of the technique, expressed as relative standard deviation, was less than $8 \%$ for HGAAS. Concentrations of total arsenic in root, seed, and soil collected from different regions were in the range of $0.01-2.82 \mathrm{mg} \mathrm{kg}^{-1}$ for $\mathrm{H}$. annuus L. growing in Turkey in 2010 and 2011.
\end{abstract}

Keywords: Helianthus annuus L., Soil, Hydride generation, Arsenic

\section{Introduction}

Arsenic (As) is known to be one of the most toxic elements and has serious health effects on humans, plants, and animals. It can exist in inorganic form as arsenite and arsenate (Elçi et al., 2008). Inorganic arsenic species are the most toxic, with arsenite being more toxic than arsenate, while the toxicities of organic arsenic species are lower, and trimethylated species are recognized as being the least toxic (Uluozlu et al., 2012). It is an environmental and food chain contaminant, and inorganic As is a class 1 carcinogen (Zhao et al., 2010); drinking water and foodstuffs are the two main common sources of inorganic As (Schoof et al., 1999; Tsuji et al., 2007).

The bioaccumulation of trace elements over large territories and long time periods, which may result in gradual damage to living organisms, necessitates careful monitoring of the input, mobility, and effects of these pollutants. Metal-accumulating plants, such as Brassica sp. and Helianthus annuus L., can accumulate unusually high concentrations of trace elements in both shoots and roots from polluted soil and waters (Dushenkov et al., 1995; Chaturvedi et al., 2006; Singh and Ma, 2006; Rosas et al., 1999; Delowar et al., 2005). In plants, arsenic is accumulated mainly in the root system, to various degrees in the above ground organs, depending upon its translocation (Zhong et al., 2011; Mei et al., 2012). 
Atomic absorption spectrometry (AAS) has been widely used for arsenic determination at trace levels, including techniques such as electrothermal atomic absorption spectrometry (ETAAS) and hydridegeneration atomic absorption spectrometry (HGAAS) (Ricardo et al., 2002). HGAAS is often used for the determination of arsenic trace levels in water (Francesconi and Kuehnelt, 2004; Burguera and Burguera, 1997; Hung et al., 2004). This analytical method is the most widely accepted procedure for the analysis of arsenic at the $\mu \mathrm{g} \mathrm{L}^{-1}$ level. For determination of arsenic, antimony, and selenium by the method of hydride generation and in situ concentration in a graphite tube, successful modifiers of the tube surface are palladium compounds, magnesium compounds, nickel compounds, iridium and zirconium (Cabon and Cabon, 2000; De-qiang et al., 1997; Matusiewicz and Sturgeon, 1996; Haug and Liao, 1996; Denkhaus et al., 1998; Bermejo-Barrera et al., 1998). Combining flow injection (FI) with flame atomic absorption spectrometry (FAAS) results in a powerful analytical tool offering important advantages over conventional FAAS. The very successful combination of FI with FAAS is mainly based on three aspects of FI. First, $\mathrm{FI}$ can be used as a sample managing system, offering the automation of chemical proceeding such as addition of reagents, dilution, preconcentration and separation. Second, $\mathrm{FI}$ can be used as a sample introduction system, offering the possibilities of micro-volume sampling and of introducing samples with high solids content or high viscosity and thereby decreasing transport interferences significantly. Third, FI can be used as part of an integrated system, offering additional information for calibration, interferences correction and feedback control. Consequently, FI can improve the performance of many features of FAAS such as sample consumption and throughput, matrix tolerance, selective, sensitivity and working range, and can enhance the accuracy and precision of methods by automated chemical processing (Sperling et al., 1992). The release of the analyte from the matrix (particularly important for environmental samples) allows the detection of very low concentrations of arsenic, antimony, and selenium, importantly at levels of their natural occurrence in the environment, without the need for preliminary preparation of samples (Matusiewicz and Sturgeon, 1996).

Ergene River Basin is one of the most important agricultural areas of Turkey and has very fertile soils. The organic matter content of the topsoil is normally low. Intensive use of the region for agriculture, strong increase of the population in connection with industrialization, and opening the farmlands to urbanization means a high risk of polluting the soil with heavy metals and other harmful substances (Coşkun et al., 2006). The Ergene River Basin in the Trakya region in Turkey is subjected to a high level of industrialization, with about 500 industrial sectors present. The intense industrialization in the region causes significant pollution throughout the area; major sectors include textiles, leather, nourishment, and chemicals.

The aim of this work is to investigate the arsenic contamination in sunflower plant and agricultural soils in Ergene River Basin. For this purpose was to determine the levels of arsenic by HGAAS in soil and sunflower plants collected from the Ergene River Basin. The Ergene River Basin was selected as the study location because the sunflower plant is the most important agriculture plant in this region. Specifically, there is no record of any information on the arsenic contents of sunflower in this region.

\section{Materials and methods}

A CEM MARSXpress 5 closed-vessel microwave digestion system with an HP500 rotor (CEM, Matthews, NC, USA) with pressure and temperature monitoring was used for microwave-assisted extraction of arsenic species from Helianthus annuus $\mathrm{L}$.

HGAAS measurements were performed with a Perkin Elmer AAnalyst 800 atomic absorption spectrometer equipped with an MHS-15 (mercury hydride system) hydride generator. All measurements were carried out using high-purity argon. An electrodeless discharge lamp for As (EDL System, Perkin Elmer) was used as the radiation source. The HGAAS working program is given in Table 1.

Analytical-grade reagents were used exclusively. Deionized water with a specific resistivity of $18.2 \mathrm{M} \Omega$ $\mathrm{cm}$ from an ELGA water purification system was used for the preparation of standards and modifier solutions. All containers and glassware were soaked in $1.4 \mathrm{M}$ nitric acid for at least $24 \mathrm{~h}$ and were hand- 
rinsed three times with water before use. Nitric acid (65\%, w/v; Merck) was further purified by sub-boiling distillation.

Table 1. Hydride-generation atomic absorption spectrometry (HGAAS) working program for arsenic measurement

\begin{tabular}{ll}
\hline Method variable & Setting \\
\hline Lamp & Electrodeless discharge \\
\hline Wavelength & $193.7 \mathrm{~nm}$ \\
\hline Flame & Air/acetylene \\
\hline Atomizer & Preheated quartz tube atomizer \\
\hline Mobile gas & Argon \\
\hline Mobile gas pressure & $2-2.5 \mathrm{bar}$ \\
\hline Reaction time & $20 \mathrm{~s}$ \\
\hline Postreaction purge time & $40 \mathrm{~s}$ \\
\hline Prereaction purge time & $50 \mathrm{~s}$ \\
\hline Air pressure & $200 \mathrm{kPa}$ \\
\hline
\end{tabular}

The working standards were prepared by serial dilution of a $1000 \mathrm{mg} \mathrm{L}^{-1}$ As stock solution (Merck) with $0.15 \mathrm{M} \mathrm{HCl}$. Aqueous solutions of sodium tetrahydroborate $\left(\mathrm{NaBH}_{4}\right)(3 \%, \mathrm{w} / \mathrm{v})$ were freshly prepared by dissolving the solid reagent in $\mathrm{NaOH}(1 \%, w / v ;$ Merck) solution. Pre-reducing solutions containing potassium iodide $(3.0 \%, \mathrm{w} / \mathrm{v})$ and ascorbic acid $(5.0 \%, \mathrm{w} / \mathrm{v})$ in water were prepared fresh every day. A solution of antifoaming agent ( $0.1 \%$, v/v; Silicon Antifoaming Agent, Merck) was prepared in $0.15 \mathrm{M}$ hydrochloric acid. Other inorganic reagents included $\mathrm{HNO}_{3}$ (Merck), $\mathrm{H}_{2} \mathrm{O}_{2}$ (Merck), and $\mathrm{HF}$ (Merck). The standard reference materials used in the experimental studies were NIM-GBW07404 (GSS-4) for soil and WEPAL-IPE-168 for sunflower seed.

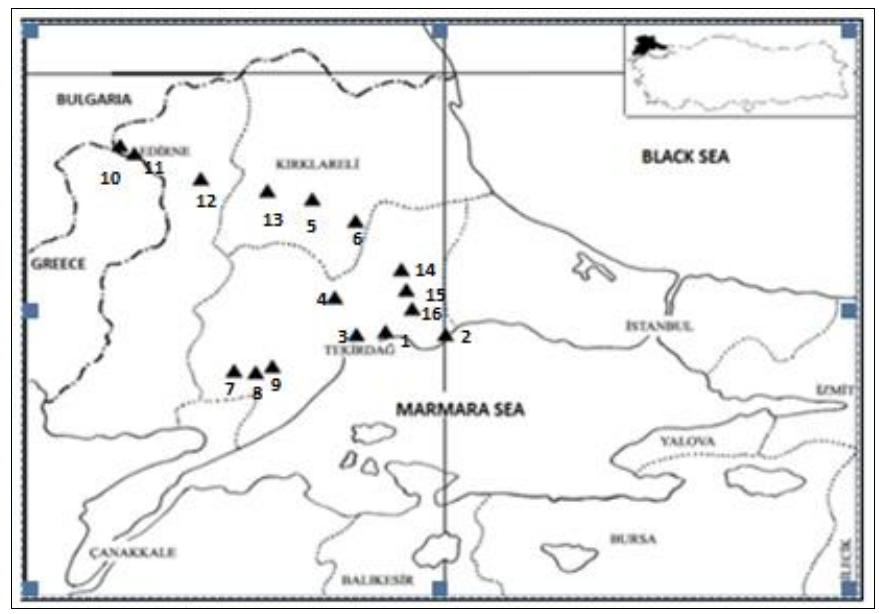

Figure 1. Sampling zones for soil and Helianthus annuus L. samples (Location 1-4, 7-9, 14-16: leather, oil, mine and stone quarry, textile, paint, metal, cheese factories. Location 5, 6: windowpane, glass, textile, paint, ice cream and paper factories. Location 10-13: textiles, paper, oil factories)

Plant and soil samples were collected from nominated locations within the Ergene River Basin. Samples were collected during August-September of 2010 and again during August-September in 2011; 18 samples (18 root and 18 plant) were collected from 16 stations, with a total of 216 environmental samples (soil, root, seed) (see Fig. 1). Samples were collected in parallel to minimize sampling error. Plant samples were washed with deionized water and divided into root and seed parts using a plastic knife. Then the washed plant parts were dried at $105^{\circ} \mathrm{C}$ for $30 \mathrm{~min}$ and at $60^{\circ} \mathrm{C}$ for $24 \mathrm{~h}$, before being ground and homogenized. 
Soil samples were also collected at the locations used for plant sampling. Soil was collected from a depth range of approximately $0-15 \mathrm{~cm}$. The samples were dried at $110^{\circ} \mathrm{C}$, ground to pass through a 200 -mesh sieve, and transferred to high-density polyethylene (HDPE) bottles.

A microwave-assisted digestion procedure was used to achieve a shorter digestion time. Environment samples of each variety $(0.5 \mathrm{~g})$ were analyzed in parallel. The sample was placed in a $50 \mathrm{ml} \mathrm{HDPE}$ flask and $8.0 \mathrm{ml}$ of a mixture of acid and oxidant, $\mathrm{HNO}_{3}(65 \%)$ and $\mathrm{H}_{2} \mathrm{O}_{2}(30 \%)(6: 2$ ratio) was added. Each flask was maintained at room temperature for $1 \mathrm{~h}$, then placed in a covered Teflon container, and placed in a microwave oven to decompose the organic matter. After cooling, the resulting solution was filtered and diluted with deionized water up to $50 \mathrm{ml}$ in a volumetric flask and kept as a stock sample solution. A blank was carried out through both procedures.

A pre-reduction step was necessary to reduce any pentavalent arsenic to its trivalent form before hydride generation. Concentrated hydrochloric acid $(0.15 \mathrm{ml})$ and $1.0 \mathrm{ml}$ of pre-reducing agent mixture [potassium iodide $(3 \%, \mathrm{w} / \mathrm{v})$, ascorbic acid $(5 \%, \mathrm{w} / \mathrm{v})]$ were added to $1.0 \mathrm{ml}$ of the digested sample, and the volume was then increased to $10 \mathrm{ml}$ with deionized water. After $60 \mathrm{~min}$ at room temperature, the sample was analyzed by HGAAS for arsenic concentration. The calibration solutions were prepared in the same way by employing $1.0 \mathrm{ml}$ aliquots of standard solution.

After pre-reduction, samples and standard solutions $(10 \mathrm{ml})$ were transferred to a reaction vessel connected to the HG system. For determination of As by HGAAS, gaseous hydrides were generated in a continuous flow system using $1.25 \mathrm{ml}$ of $\mathrm{NaBH}_{4}$ solution $(3.0 \%, \mathrm{w} / \mathrm{v})$ stabilized with $\mathrm{NaOH}(1.0 \%, \mathrm{w} / \mathrm{v})$ and $0.15 \mathrm{M} \mathrm{HCl}(1.5 \%)$ as carrier solution. The $\mathrm{NaBH}_{4}$ and $\mathrm{HCl}$ flow rates were set to $2.0 \mathrm{ml} \mathrm{min}{ }^{-1}$, while the flow rates of sample solutions or standard solutions were set to $5.0 \mathrm{ml} \mathrm{min}{ }^{-1}$. The resulting mixture was transferred into the gas-liquid separator from where the gaseous hydrides were transported to the quartz tube atomizer of the AAS heated with flame. When the performance of the HGAAS measurements deteriorated, the quartz tube was conditioned by soaking in concentrated hydrofluoric acid for $10 \mathrm{~min}$. The quartz tube was subsequently rinsed three times with high-purity water and allowed to dry at room temperature. Prior to any further determinations of As, the HGAAS was checked for optimum signal intensity and stability by measuring a $2 \mu \mathrm{g} \mathrm{I} \mathrm{I}^{-1} \mathrm{As}(\mathrm{III})$ standard solution.

\section{Results and discussion}

Arsenic occurs naturally in rocks and soil, water, air, and plants and animals. It can be further released into the environment through natural activities such as volcanic action, erosion of rocks and forest fires, or through human actions. High arsenic levels can also come from certain fertilizers and animal feeding operations. Industry practices such as copper smelting, mining and coal burning also contribute to arsenic in our environment (EPA, 2012).

In this study, the concentrations of As were measured in soil, sunflower root, and sunflower seed by HGAAS for samples collected from the Ergene River Basin in 2010 and 2011.

The results of soil obtained in this work are also compared with the same location for Trakya (Coşkun et al., 2006). Results show good agreement for soil. Coşkun et al. (2006) reported that the highest values of As are observed in samples from the Istanbul district and from areas near the Bulgaria border. The lowest and highest concentrations of As are 1.9 and $51 \mathrm{mg} \mathrm{kg}^{-1}$ respectively. However, according to them the obtained concentrations of As are between the limitation values of EEA for natural soil value. Concentrations of arsenic in soils were reported as $5-40 \mathrm{mg} \mathrm{kg}^{-1}$ by Nriagu (1994). Fitz and Wenzel (2002) reported that arsenic occurs naturally in soils at concentrations ranging from 0.1 to $40 \mathrm{mg} \mathrm{kg}^{-1}$. Arsenic in US soils ranges from 2 to $200 \mathrm{mg} \mathrm{kg}^{-1}$, with $5 \mathrm{mg} \mathrm{kg}^{-1}$ as the mean, and the mean for Florida soils is $0.4 \mathrm{mg}$ $\mathrm{kg}^{-1}$. The baseline As concentration for Florida soils is $0.02-7.01 \mathrm{mg} \mathrm{kg}$ (Chen et al., 1999).

In this study, we found that the arsenic concentration in soil samples collected in 2010 ranged from 0.07 to $1.84 \mathrm{mg} \mathrm{kg}^{-1}$, with a mean of $0.65 \pm 0.34 \mathrm{mg} \mathrm{kg}^{-1}$ (Fig. 2). The same analysis for 2011 soil samples showed arsenic levels that ranged from 0.12 to $1.58 \mathrm{mg} \mathrm{kg}^{-1}$, with a mean of $0.89 \pm 0.38 \mathrm{mg} \mathrm{kg}^{-1}$ (Fig. 3). 
The uptake of As by maize, ryegrass, rape, and sunflower from arsenic-contaminated soil was studied in a pot experiment in the greenhouse (Gulz, 2002). In all soil-plant combinations, most As was accumulated in the roots. Although accumulation above ground remained lower than below ground, the As concentrations in stems, leaves, and seeds were above the Swiss tolerance limits for food or fodder crops (0.2 and $4 \mathrm{mg} \mathrm{As} \mathrm{kg}^{-1}$, respectively), except for maize (Gulz, 2002).

In this investigation, arsenic contents in the roots of Helianthus annuus L. for samples collected in 2010 (Fig. 2) ranged from 0.01 to $1.82 \mathrm{mg} \mathrm{kg}^{-1}$, with a mean of $0.70 \pm 0.38 \mathrm{mg} \mathrm{kg}^{-1}$. The As levels in the seeds ranged from 0.07 to $1.67 \mathrm{mg} \mathrm{kg}^{-1}$, with a mean of $0.86 \pm 0.51 \mathrm{mg} \mathrm{kg}^{-1}$.

For 2011 samples (Fig. 3), arsenic contents in the roots of H. annuus L. ranged from 0.31 to $2.82 \mathrm{mg} \mathrm{kg}^{-1}$, with a mean of $0.96 \pm 0.48 \mathrm{mg} \mathrm{kg}^{-1}$. The As levels in the seeds ranged from 0.21 to $2.10 \mathrm{mg} \mathrm{kg}^{-1}$, with a mean of $0.89 \pm 0.43 \mathrm{mg} \mathrm{kg}^{-1}$.

Considered by locations, arsenic values were higher in the 7-9 location than location of others. The reason is that more intensive agricultural area and can be use large amounts of pesticides. 1-4 and 10-13 locations are also in second place. Mines and quarries are mainly located in these regions, textiles, metals, oil and paper mills can be sources of arsenic. Arsenic became widely used as a pesticide in the wake of the industrial revolution. This usage reached a maximum in the 1950s. Then it was progressively and largely replaced by organochlorine pesticide (Azcue and Nriagu, 1994). Nevertheless, the major use of arsenic today is still in the agricultural field. For industrial purposes, arsenic is primarily used in the form of arsenic trioxide. Industrial uses include the manufacture of ceramics and glass, electronics, pigments and antifouling agents, cosmetics and fireworks (Leonard, 1991).

Table 2. Mean arsenic concentrations by location

\begin{tabular}{ccccccc}
\hline & \multicolumn{6}{c}{ As $\left(\mathbf{m g ~ k g}^{-\mathbf{1}}\right)$} \\
\hline Location & Soil & Root & Seed & Soil & Root & Seed \\
\hline $1-4$ & 0.73 & 0.65 & 0.54 & 1.42 & 0.95 & 0.87 \\
\hline $5-6$ & 0.54 & 0.72 & 0.91 & 0.81 & 1.01 & 0.83 \\
\hline $7-9$ & 0.61 & 0.48 & 0.97 & 1.03 & 1.52 & 0.99 \\
\hline $10-13$ & 0.75 & 0.94 & 1.17 & 0.54 & 0.87 & 0.96 \\
\hline $14-16$ & 0.55 & 0.76 & 0.77 & 0.94 & 0.59 & 0.81 \\
\hline
\end{tabular}

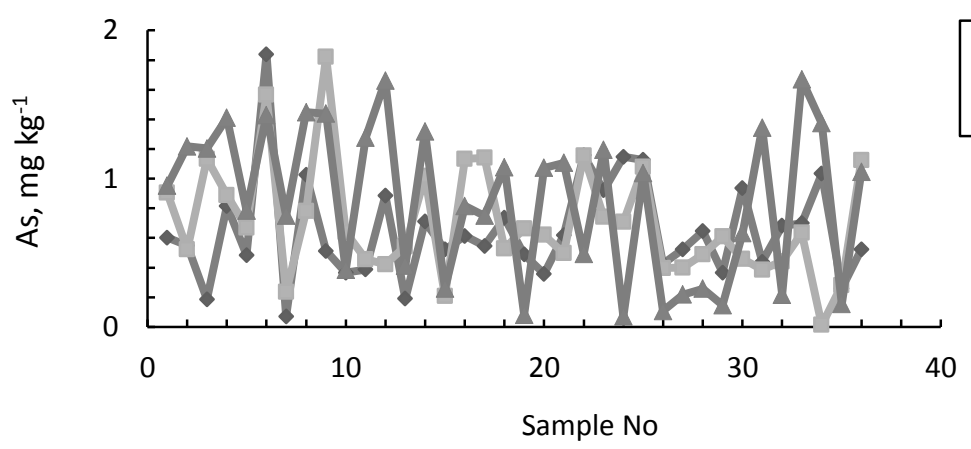

Figure 2. Contents of arsenic in soil and H. annuus L. samples collected in 2010, measured by hydridegeneration atomic absorption spectrometry (HGAAS)

The detection limit (limit of detection, LOD) was calculated in accordance with the IUPAC definition (Sperling et al., 1992) on the basis of three times the standard deviation of the blank signal. LOD calculated were: $0.02 \mathrm{mg} \mathrm{kg}^{-1}$ for As.

The upper limit of the linear range of the calibration curve for the HGAAS method was $2.5 \mu \mathrm{g} \mathrm{I}^{-1}$ $\left(r^{2}=0.9997\right)$. The accuracy of the procedure was checked by the analysis of the standard reference 
materials. Reference materials for soil [(NIM-GBW07404 (GSS-4)] and sunflower seed (WEPAL-IPE-168) were also analyzed by these techniques for comparison. The results are given in Table 2 . It is evident that the concentrations of arsenic determined agreed well with reported certified confirming the accuracy of the procedure applied.

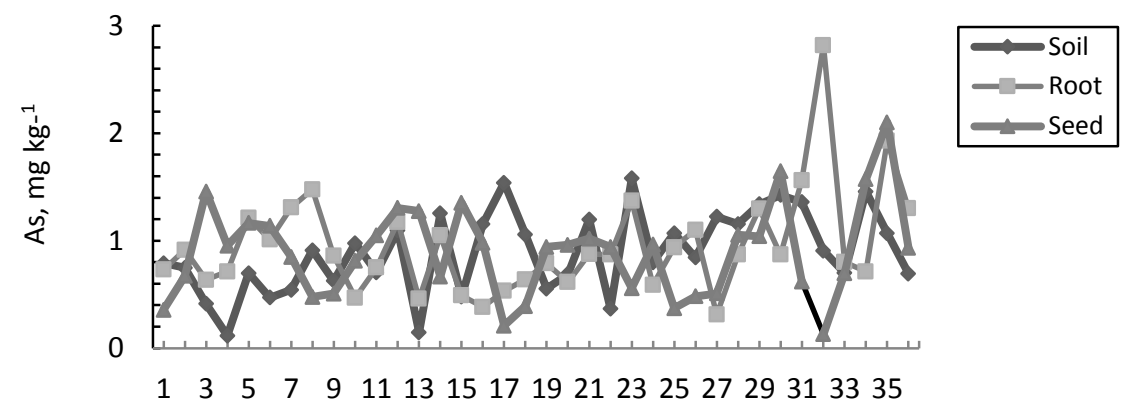

Sample No

Figure 3. Contents of arsenic in soil and $H$. annuus $L$. samples collected in 2011 , measured by HGAAS

Table 3. Validation data for reference materials for the HGAAS method $(n=5)$

\begin{tabular}{ccc}
\hline \multirow{2}{*}{ Sample } & \multicolumn{2}{c}{ As $\left(\mu \mathrm{g} \mathrm{g}^{-1}\right)$} \\
\cline { 2 - 3 } & Certified value & HGAAS \\
\hline NIM-GBW07404(GSS-4) & $58.0 \pm 6.0$ & $57.6 \pm 5.2$ \\
WEPAL-IPE-168 & $69.1 \pm 8.45$ & $66.2 \pm 6.20$ \\
\hline
\end{tabular}

The HGAAS technique is based on the reaction of $\mathrm{NaBH}_{4}$ with the acidified sample and separation of the analyte as a hydride from the matrix before measurement. This is one of the principal advantages of this technique, because it significantly reduces the possibility of interference. A summary of mean arsenic levels in environment samples is shown in Table 3. Although a large number of recent studies have drawn attention to the contents of trace elements in soils and plants, our study is original because no such study has been carried out to date in the Ergene River Basin, Turkey.

Table 4. Mean arsenic concentrations in environment samples

\begin{tabular}{cccc}
\hline \multirow{2}{*}{ Year } & \multicolumn{3}{c}{ As $\left(\mathrm{mg} \mathrm{kg}^{-1}\right)$} \\
\cline { 2 - 4 } & Soil & Root & Sunflower seed \\
\hline 2010 & $0.65 \pm 0.34$ & $0.70 \pm 0.38$ & $0.86 \pm 0.51$ \\
2011 & $0.89 \pm 0.38$ & $0.96 \pm 0.48$ & $0.89 \pm 0.43$
\end{tabular}

Results of 2010 and 2011 of arsenic in the samples were compared statistically. SPSS version 10.0 was used for this purpose. According to Pearson correlation, the values found 0.05 for soil, 0.33 for roots, 0.30 for seeds and were interpreted as weak.

\section{Conclusions}

In our analysis of environmental samples taken from the Ergene River Basin in Turkey, arsenic concentrations determined by HGAAS were found to be compatible with literature data. The results obtained for the soil samples, based on Soil Pollution Control Regulations (in Turkey) were under the specified limits (upper limit for As: $20 \mathrm{mg} \mathrm{kg}^{-1}$ ). The data obtained for arsenic content in the plant samples were consistent with literature data. Arsenic contents measured in 2011 samples were found to be higher than those in samples collected in 2010. Metal-accumulating plants, such as Helianthus annuus L., can accumulate trace elements in its shoots and roots from polluted soils. In this study, the arsenic levels in samples of root were higher than those in soil, suggesting that $H$. annuus $\mathrm{L}$. accumulated arsenic from the 
soil. In 2010 samples, arsenic levels in seeds were higher than those in roots, which may be an indication of atmospheric pollution. In general, the As concentrations in samples of soil, root, and seed varied from 0.01 to $2.82 \mathrm{mg} \mathrm{kg}^{-1}$ and are within the normal levels.

The concentrations of arsenic in $H$. annuus $L$. can be successfully measured by HGAAS. The short analysis time, low cost, and the ability to exclude matrix interferences are significant advantages of the HGAAS technique.

\section{Acknowledgments}

This work was supported by the Scientific Research Unit of the University of Trakya (Project No. 2011/30).

\section{References}

Azcue J.M. and Nriagu J.O. (1994), Arsenic: historical pespectives, In: Arsenic in the environment, Nriagu J.O. (ed), John Wiley \& Sons, New York.

Bermejo-Barrera P., Moreda-Pineiro J., Moreda-Pineiro A. and Bermejo-Barrera A. (1998), Selective medium reactions for the 'arsenic(III)', 'arsenic(V)', dimethylarsonic acid and monomethylarsonic acid determination in waters by hydride generation on-line electrothermal atomic absorption spectrometry with in situ preconcentration on Zr-coated graphite tubes, Analytica Chimica Acta, 374, 231-240.

Burguera M. and Burguera J.L. (1997), Analytical methodology for speciation of arsenic in environmental and biological samples, Talanta, 44, 1581-1604.

Cabon J.Y. and Cabon N. (2000), Determination of arsenic species in seawater by flow injection hydride generation in situ collection followed by graphite furnace atomic absorption spectrometry, stability of As(III), Analytica Chimica Acta, 418, 19--31.

Chaturvedi I. (2006), Effects of arsenic concentrations and forms on growth and arsenic uptake and accumulation by indian mustard (brassica juncea I.) genotypes, Journal Central European Agriculture, 7, 31-40.

Chen M., Ma L. and Harris W. (1999), Baseline concentrations of 15 trace elements in Florida surface soils, J. Environ. Qual., 28, 1173-1181.

Coşkun M., Steinnes E., Frontasyeva Viladimirovna M., Stobakk Eidhammer T. and Demkina S. (2006), Heavy metal pollution of surface soil in the Thrace Region, Turkey, Environmental Monitoring and Assessment, 119, 545-556

Denkhaus E., Golloch A., Kampen T.U., Nierfeld M. and Telgheder U. (1998), Electrolyte hydride generation electrothermal atomic absorption spectrometry-in situ trapping of As on different pre-conditioned end-heated graphite tubes, Fresenius Journal of Analytical Chemistry, 361, 733-737.

Delowar H.K.M., Yoshida I., Harada M., Sarkar A.A., Miah M.N.H., Razzaque A.H.M., Uddin M.dl, Adhana K. and Perveen Mst F., (2005), Growth and uptake of arsenic by rice irrigated with As-contaminated water, Journal of Food Agriculture and Environment, 3, 287-291.

De-qiang Z., Han-wen S. and Li-li Y. (1997), Determination of trace inorganic selenium in organoselenium (selenosugar) oral nutrition liquids by graphite furnace atomic absorption spectrometry with hydride generation, Fresenius Journal of Analytical Chemistry, 359, 492-496.

Dushenkov V., Kumar P.B.A., Motto H. and Raskin I. (1995), Rhizofiltration: the use of plants to remove heavy metals from aqueous streams, Environmental Science \& Technology, 29, 1239-1245.

Elçi L., Divrikli U. and Soylak M. (2008), Inorganic arsenic speciation in various water samples with GF-AAS using coprecipitation, International Journal of Environmental Analytical Chemistry, 88, 711-723.

http://water.epa.gov/lawsregs/rulesregs/sdwa/arsenic/Basic-Information.cfm

Fitz W.F. and Wenzel W.W. (2002), Arsenic transformations in the soil-rhizosphere-plant system: fundamentals and potential application to phytoremediation, Journal of Biotechnology, 99, 259-278.

Francesconi K.A. and Kuehnelt D. (2004), Determination of arsenic species: a critical review of methods and applications, 2000-2003, Analyst, 129, 373-395.

Gulz P.A. (2002), Arsenic Uptake of Common Crop Plants from Contaminated Soils and Interaction with Phosphate, Swiss Federal Institute of Technology Zurich, Diss ETHNo. 14879. 
Haug H.O. and Liao Y.P. (1996), Investigation of the automated determination of As, Sb and Bi by flow-injection hydride generation using in-situ trapping on stable coatings in graphite furnace atomic absorption spectrometry, Fresenius Journal of Analytical Chemistry, 356, 435-444.

Hung D.Q., Nebrassova O. and Compton R.G. (2004), Analytical methods for inorganic arsenic in water: a review, Talanta, 64, 269-277.

Leonard A. (1991), Arsenic, in Merian, Ernest, (ed), Metals and Their Compounds in the Environment: Weinheim, Germany.

Matusiewicz H. and Sturgeon R.E .(1996), Atomic spectrometric detection of hydride forming elements following in situ trapping within a graphite furnace, Spectrochimica Acta Part B, 51, 377-456.

Mei L., Wan X., Huang Z., Chen T., Li X. and Liu Y. (2012), First evidence on different transportation models of arsenic and phosphorus in arsenic hyperaccumulator Pteris vittata, Environmental Pollution, 161, 1-7.

Nriagu J.O. (1994), Arsenic in the Environment Part I: Cycling and Characterization, Wiley, New York.

Ricardo J.C., Otoniel D.A. and Ricardo E.S. (2002), Determination of arsenic in petroleum refinery streams by electrothermal atomic absorption spectrometry after multivariate optimization based on Doehlert design, Spectrochimica Acta Part B, 57, 1967-1978.

Rosas I., Belmont R., Armienta A. and Baez A. (1999), Arsenic Concentrations in Water, Soil, Milk and Forage in Comarca Lagunera, Mexico, Water, Air, \& Soil Pollution, 112,133-149.

Schoof R.A., Yost L.J., Eickhoff J., Crecelius E.A., Craign D.W., Meacher D.M. and Menzel D.B. (1999), A market basket survey of inorganic arsenic in food, Food and Chemical Toxicology, 37, 839-846.

Singh N. and Ma L.Q. (2006), Arsenic speciation, and arsenic and phosphate distribution in arsenic hyperaccumulator Pteris vittata and on-hyperaccumulator Pteris ensiformis, Environmental Pollution, 141, 238-246.

Sperling M., Koscielniak P. and Welz B., (1992), Improvement of detection limits for flow-injection flame atomic absorption spectrometry by dedicated signal processing, Analytica Chimica Acta, 261, 115-123.

Tsuji J.S., Yost L.J., Barraj L.M., Scrafford C.G. and Mink P.J. (2007), Use of background inorganic arsenic exposures to provide perspective on risk assessment results, Regulatory Toxicology and Pharmacology, 48, 59-68.

Uluozlu O.D., Tuzen M., Durali M. and Soylak M. (2010), Determination of As(III) and As(V) species in some natural water and food samples by solid phase extraction on Streptococcus pyogenes immobilized on Sepabeads SP 70 and hydride generation atomic absorption spectrometry, Food and Chemical Toxicology, 48, 1393-1398.

Zhao F., Stroud J.L., Eagling T., Dunham S.J., Mcgrath S.P. and Shewry P.R. (2010), Accumulation, distribution, and speciation of arsenic in wheat grain, Environmental Science \& Technology, 44,5464-5468.

Zhong L., Hu C., Tan Q., Liu J. and Sun X. (2011), Effects of sulfur application on sulfur and arsenic absorption by rapeseed in arsenic contaminated soil, Plant Soil Environ., 57, 429-434. 